\title{
LAND COVER AND SEDIMENT LAYERS AS CONTROLS OF INLET BREACHING
}

\author{
M.O. Kurum ${ }^{1}$, M. Overton ${ }^{1}$ and H. Mitasova ${ }^{2}$
}

Understanding the processes that take place during a storm leading to coastal morphological change has been a challenging topic for coastal engineers. Over the years, many models have been developed to predict the coastal response to storms evolving from the one dimensional empirical models to two or three dimensional process based models. We hypothesized that the predictive capacity of these models can be improved by incorporating the site specific effect of the land cover features that are in place at the time of the storm. In this work, we present a case study of the development of the Pea Island breach, Outer Banks, North Carolina during Hurricane Irene in August 2011. The inclusion of the land cover effects into the model significantly improves the predictive capability of the model results.

Keywords: XBeach; land cover; Hurricane Irene; Pea Island breach

\section{INTRODUCTION}

Catastrophic hurricanes in the U.S., Katrina in 2005, Ike in 2008 and Irene in 2011 pose a threat to the safety, economy, natural resources and infrastructure of coastal communities due to a wide range of impacts. Of these impacts, landform change, can present a unique set of considerations if the event represents a tipping point for the landform in question. This tipping point is usually tied to the relationship of the natural forcing mechanism of a storm (waves, tides, storm surge and run-up) to the pre-existing foredune and beach topography (Morton, 2002; Wright et al., 1970). Given the costly impacts of storm events, it is no surprise that many researchers have been interested in predicting the landform changes during such events through numerical modeling the natural processes caused by a storm to predict the post topographic configuration. Over the past years, Kriebel and Dean (1985), Krause and Wise (1993), Larson et al., (1989, 2001, 2004, and 2005), Roelvink (1993) and Vellinga, (1983 and 1986) introduced beach profile evolution models to predict coastal response to storms. Over time, these models evolved from being empirical based to process based, however, lacked the ability to assess the more complex case of significant alongshore variability. With the advancements in twodimensional, depth-averaged (2DH) models (e.g., Lesser et al., 2004; Reniers et al., 2004, 2006; Van Dongeren et al., 2003; Roelvink et al., 2009) and the increasing availability of computational power, it is more beneficial to represent the coastal topography and hydrodynamic conditions that will interact with it in its entire cross shore and along shore complexity in order to create more comprehensive coastal zone management solutions and to conduct research to better understand the processes that take place during storms. XBeach (Roelvink et al., 2009) is a two-dimensional, numerical, wave group resolving, morphological model developed to solve the nearshore storm condition hydrodynamics and to calculate the landform changes caused by dune erosion, overwash and breaching. The model has been successfully applied to cases on barrier islands (Lindemer et al., 2010; McCall et al., 2010) with relatively high dunes where storm driven overwash is an important process. The modeled cases are represented with one type of sediment, sand in the studies cited above, however, vegetation types, densities and sediment properties play an important role on the morphological change patterns (Wang et al., 2006; Wang and Horwitz, 2007). Our motivation in this work is to extend these studies by identifying key land cover types and to develop procedures that model the land cover effect on storm driven morphological response of barrier islands. The modeling framework utilized is XBeach and realistic results are achieved by hypothesizing approaches and testing against field results at a location with land cover variability and where considerable morphological change (including overwash and breaching) has occurred. A variety of both pre and post storm geospatial data support the study.

\section{STUDY SITE}

The study site, Pea Island breach location, selected for this work is located on the North Carolina Outer Banks (OBX) barrier island system (Figure 1) that separates the Atlantic Ocean from Pamlico Sound. The breach was opened by Hurricane Irene on August 27, 2011 and is in the vicinity of what is known as New Inlet, an inlet that has opened and closed multiple times (within an approximate $5 \mathrm{~km}$ alongshore distance) in the last 100 years. The area in and around the study site is within the U.S. Fish and Wildlife Service Pea Island National Wildlife Refuge and is primarily undeveloped with the exception of the two-lane shore parallel road (NC 12) and a group of refuge maintenance buildings and

\footnotetext{
${ }^{1}$ Department of Civil, Construction and Environmental Engineering, North Carolina State University, Raleigh, NC 27695, USA

${ }^{2}$ Department of Marine, Earth and Atmospheric Science, North Carolina State University, Raleigh, NC 27695, USA
} 
parking lot (Figure 2). The oceanfront dunes are seaward of the highway and have primarily been subjected to natural processes since the 1970s (Birkemeier et al., 1984). Long term shoreline erosion has reduced the width of the beach and exposed the dunes to the natural impact of storm waves and surge. In 2009, the storm conditions caused by the combination of tropical storm Ida and the high pressure system over the Northeast United States resulted in severe erosion and overwash deposits in the breach location. The location of one of the overwash fans created by this storm coincides with breach channel created by Hurricane Irene in 2011 (Figure 2).

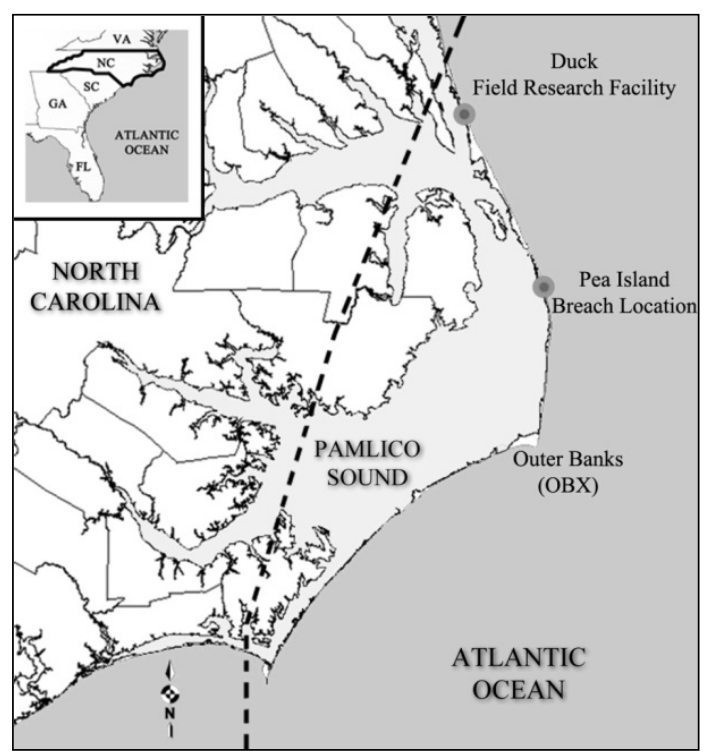

Figure 1. Study Location: Pea Island breach location on the Outer Banks of North Carolina. Hurricane Irene track (dotted line).

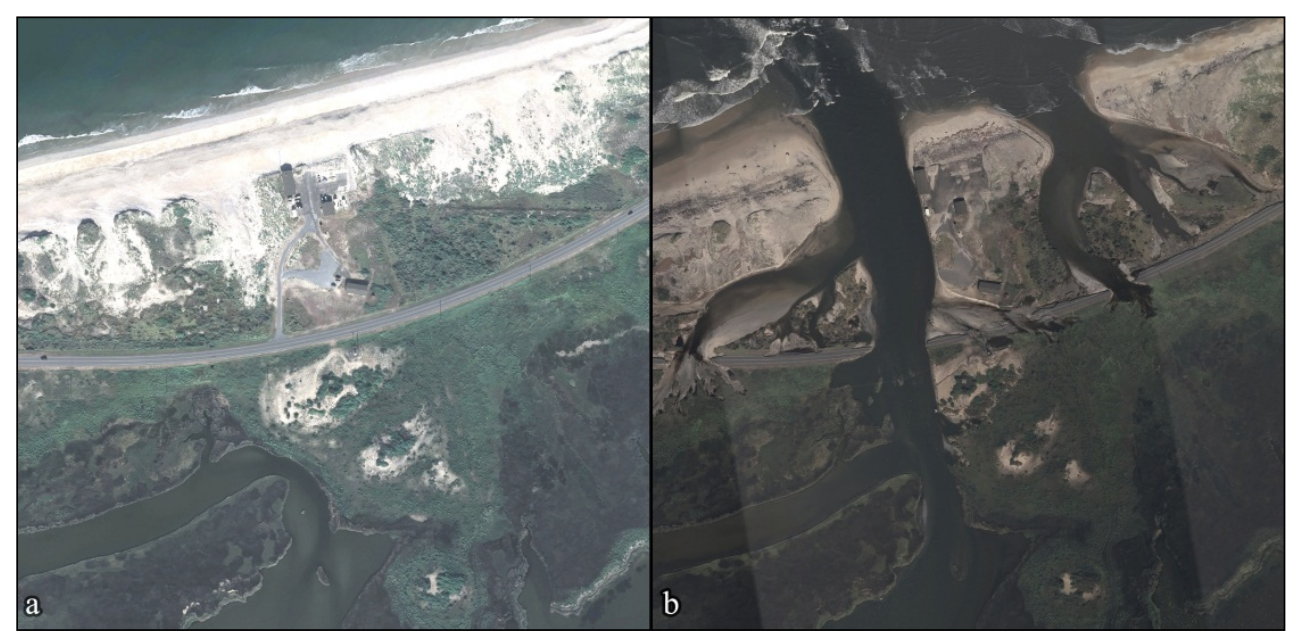

Figure 2. Pea Island Breach Location before and after Hurricane Irene. (a) August $2^{\text {nd }} 2011$ (b) August $28^{\text {th }}$ 2011. North Carolina Department of Transportation (NCDOT) imagery

\section{Hurricane Irene}

Although this location is identified as a vulnerable location to storm impact, the breaching of the island caused by Hurricane Irene was somewhat unexpected considering the Saffir-Simpson intensity of Category 1 at landfall. The hurricane made landfall near Cape Lookout and traveled north across Pamlico Sound and the Pamlico-Albemarle peninsula. While traveling through Pamlico Sound, the storm wind direction shifted from East-West direction to West-East direction (USACE 2011) which initially caused the sound side water body to be pushed west causing the sound side OBX to dry (Figure 3a). As the water body began to rebound back naturally, the direction of the hurricane winds shifted as the storm passed over Pamlico Sound and created a rapid increase in water elevation and wave formation to the east leading to significant flooding of the inland or sound side shoreline of OBX (Figure. 3b). The U.S Army Corps of Engineers Field Research Facility (FRF) in Duck recorded $1.9 \mathrm{~m}$ 
of surge in the sound side, highest measured since measurements began in 1979 (USACE 2011). The wave action is not recorded by the FRF for the sound side however the 'nowcast' runs conducted by Renaissance Computational Institute (RENCI) for The Coastal Emergency Risks Assessment (CERA) group indicated wave heights reaching up to $1.5 \mathrm{~m}$ at the study location, disappearing over time as the storm moved outside the North Carolina coastal region. Meanwhile, the surge recorded on the ocean side reached a maximum value of $0.9 \mathrm{~m}$.

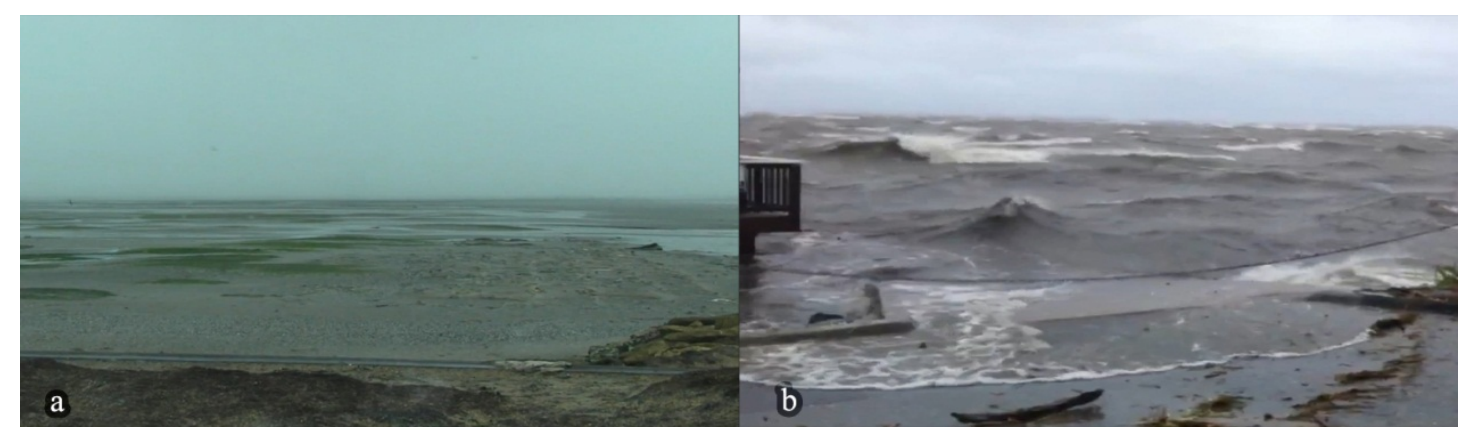

Figure 3. Sound side OBX during Hurricane Irene. (a) East-West winds pushed the waters to western Pamlico Sound drying the sound side coast. (b) Shifted winds add wave action to rebounding water body.

\section{MODELING EFFORT}

\section{Input Boundary Conditions}

Time series extracted from the recorded FRF data and the 'nowcast' model runs are used as the water level and wave inputs for the model input boundary conditions respectively (Figure 4). Note that the model boundary conditions are initiated when the sound side water level started to increase rapidly approximately at 2100UTC on August 27th. The duration of the model runs were set to approximately 60 hours to match the date and time of the post storm field survey (August $30^{\text {th }}, 2012$ ) contracted by the NCDOT for model result comparison purposes.

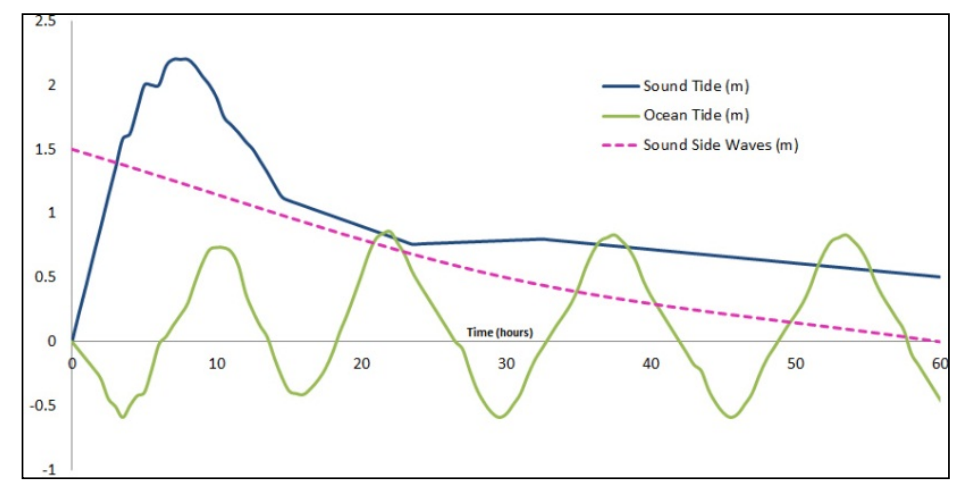

Figure 4. Water levels for the sound side and ocean side. Waves disappear in the sound side over time.

\section{Model Grid}

The study location is represented by a variable size grid with 343 (along shore) nodes and 627 (cross shore) nodes. The minimum resolution is $2 \mathrm{~m}$ along the beach and dune field and the maximum grid size is $10 \mathrm{~m}$ in the along shore direction and $20 \mathrm{~m}$ in the cross shore direction (Figure 5). The area covered by the model domain is approximately $2 \mathrm{~km}^{2}$. The cross shore extent of the domain was chosen to minimize sediment transport at the offshore and sound side boundaries (i.e., beyond the limit of expected transport). A similar criterion might optimally be chosen for the lateral boundaries; however, the extent of the storm (and sediment transport) covered most of the barrier island rendering this approach infeasible. Therefore, the elevation profiles in the cross shore direction are replicated in the along shore direction at the lateral boundaries of the domain to minimize topographic gradients that could impact significant sediment transport and thus create model instabilities.

The elevation information for model nodes is extracted from the NCDOT digital terrain model created by incorporating the field surveyed elevation data with the photogrammetrically collected terrain elevation data. The bathymetry data is incorporated into the model domain from the 2004 US Army Corps of Engineers (USACE) Topo/Bathy Lidar. For reference, NC 12 and the U.S. Fish and Wildlife Service National Wildlife Refuge maintenance buildings are noted in the figure as well. 


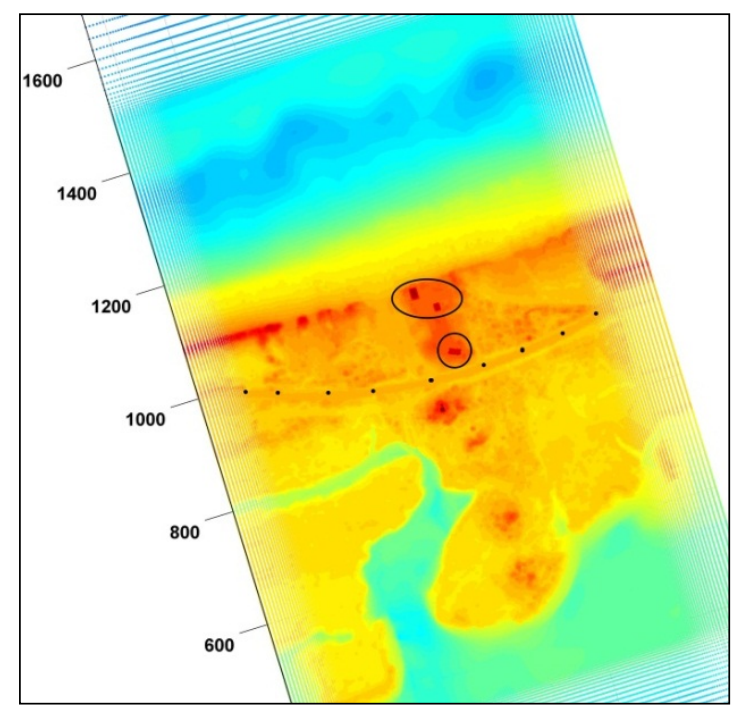

Figure 5. Model grid. NC 12 (dotted line) and the U.S. Fish and Wildlife Service maintenance buildings (marked with black circles). Ocean side (top), sound side (bottom).

\section{Sediment - Land Cover Parameters}

As mentioned in the introduction section, previous modeling efforts to study the coastal response to storm conditions represent the location in question by defining all model nodes as sand nodes. This application is not limited to the cited case studies modeled with XBeach and is very common in coastal morphological modeling as it is practical and since mostly the parts of the coast in interest are usually the nearshore, foreshore and foredune locations, is a justified approach given that the coastal area that experiences the sediment transport is mostly sandy. However, in situations where the storm induced flow interacts with the coastal hinterland and/or in situations where the overwash flow eventually leads to channelization, the effect of the land cover features are important in not only changing rates of sediment transport but also in influencing the development of the pathways of flow which in turn impact the amount of erosion (or accretion) experienced. In this study, the aim is to create a case study for the breach occurrence in the Pea Island location that provide insights on the effects of subsurface sediment layers and land cover in improvements of modeling efforts for predicting the occurrence of a breach and the post-storm configuration of the morphology. To achieve this objective, we compare the results of the simulation where the domain is represented with sand only and the results of the simulations where all model nodes are represented with their corresponding land cover feature extracted from color orthoimagery.

To categorize the study area into available land cover features, a raster of land cover classes is created using supervised radiometric classification procedures within a GIS on the pre storm orthoimagery. The user defines a land cover class based on visual interpretation of the orthoimagery for a limited set of distinct areas. Once defined, the GIS workflow processes the entire image into the defined classes (Figure 6). The assumption was that this area can be represented by defining only three land cover classes consisting sandy areas on the beach, dune face, degraded dune fields and overwash areas, vegetated areas along the landward side of the dune, marsh and roadside and the paved/concrete areas where the NC 12 passes through, parking areas and where the maintenance buildings reside. For this case, no attempt was made to differentiate builds versus pavement.

In order to differentiate the impact on sediment transport that the various land cover types influenced, a feature within XBeach originally developed to model multiple sediment layers in overwash cases was utilized. This feature allows location dependent (each grid point) specification of the D50, D90 and the sediment calibration factor (a parameter that influences the rate of sediment transport). It makes it also possible to set the number of sediment classes, number of layers and the thickness of the layers giving the ability to set up different configurations of the sediment layers.

Conceptually land cover also influences rates of transport (or erosion and accretion) of the landform. For example, a vegetated dune may erode more slowly than an unvegetated dune. A paved area will not erode until the pavement is removed. Figure 6 (bottom right) includes a basic legend to depict the configuration of each class based on the defined layer changes over depth. That is, if a model node is defined as sand on the surface of the domain, it will remain as a sand node, if it was defined as a pavement/concrete node it will change into a sand node after the erosion of the surface 
pavement/concrete layer since pavement sits on sand. A vegetation node will remain as a vegetation node after the erosion of the surface vegetation layer; it will change to a sand layer only after the second layer of vegetation is eroded. . The idea behind having two consecutive vegetation layers is to imitate the effect of root density. The underlying layers are pushed up to the surface as the surface layers erode and become the effective top surface that interacts with the flow. Note that sand and vegetation have the same grain sizes but different calibration factors. The concrete/pavement node has a significantly larger grain size with a smaller calibration factor. The sediment characteristics and the calibration factors for the vegetation and concrete/pavement classes are empirical and have no physical meaning other than trying to imitate the behavior of such land cover features. The values assigned are calibrated to improve results based on the post storm configuration of the study location.

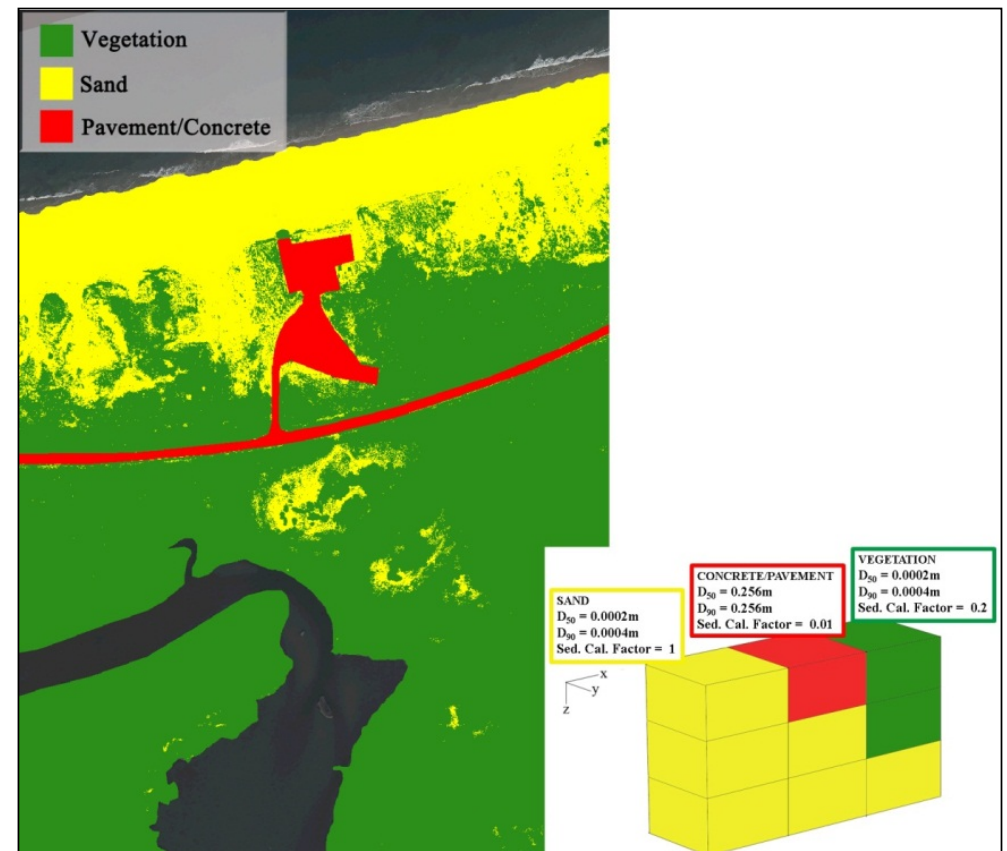

Figure 6. Raster of land cover classes (left), configuration of different class layers in relation to each other (bottom right).

\section{RESULTS}

In order to illustrate the improvement in modeling efforts made by using land cover classes, two cases are developed and results are presented. The two cases are 1) sand only case and 2) land cover using the three classes described above. The results are first presented qualitatively by visually comparing the channel location and morphology between the model outputs and the orthoimagery provided by NCDOT (Figure 7). Then, the results of both cases are compared to the NCDOT bathymetric survey carried out on August $30^{\text {th }}$, 2011 along the NC 12 highway at the breach location (Figure 8).

Figure 7 presents the model conditions visualized to illustrate topographic and bathymetric features as compared to an orthoimagery of the same location. In Figure 7a, the pre-storm conditions are illustrated. The black box or outline on the model visualization is to indicate the coverage of the orthoimagery. The model coordinates are in meters. Topography is illustrated with shades of brown; lower elevations are lighter shades. It is possible to note the corresponding features in the orthoimagery with the visualization. For example, the curved road bed is visible in the model as are the remnant dune features along the coast. In addition, the maintenance buildings are highlighted in red. This condition is the initial condition for both the sand only and land cover test cases. Figure 7b contrasts the post storm orthoimagery with the model output for the sand only case and Figure 7c contrasts the same post storm orthoimagery with the model output for the land cover case. From visual inspection of Figure 7b, it is clear that two channels are formed during the simulation in approximately the right locations; however, they appear to be much wider and more extensive than that illustrated by the orthoimagery. Model results are at for the last time step of the simulation. Standing water is color coded blue and deeper shades of blue indicate greater depths. The secondary channel (right hand side) in Figure $7 \mathrm{~b}$ is not only wider but extends further in the landward direction almost reaching the sound 
side and creating a secondary breach channel. The low elevation visible in 7a coupled with sand only model parameters can explain the increased vulnerability modeled by this simulation. The real prestorm conditions (Figure 7a) illustrate extensive vegetation both on the seaward and landward sides of the road that could provide mitigating properties.

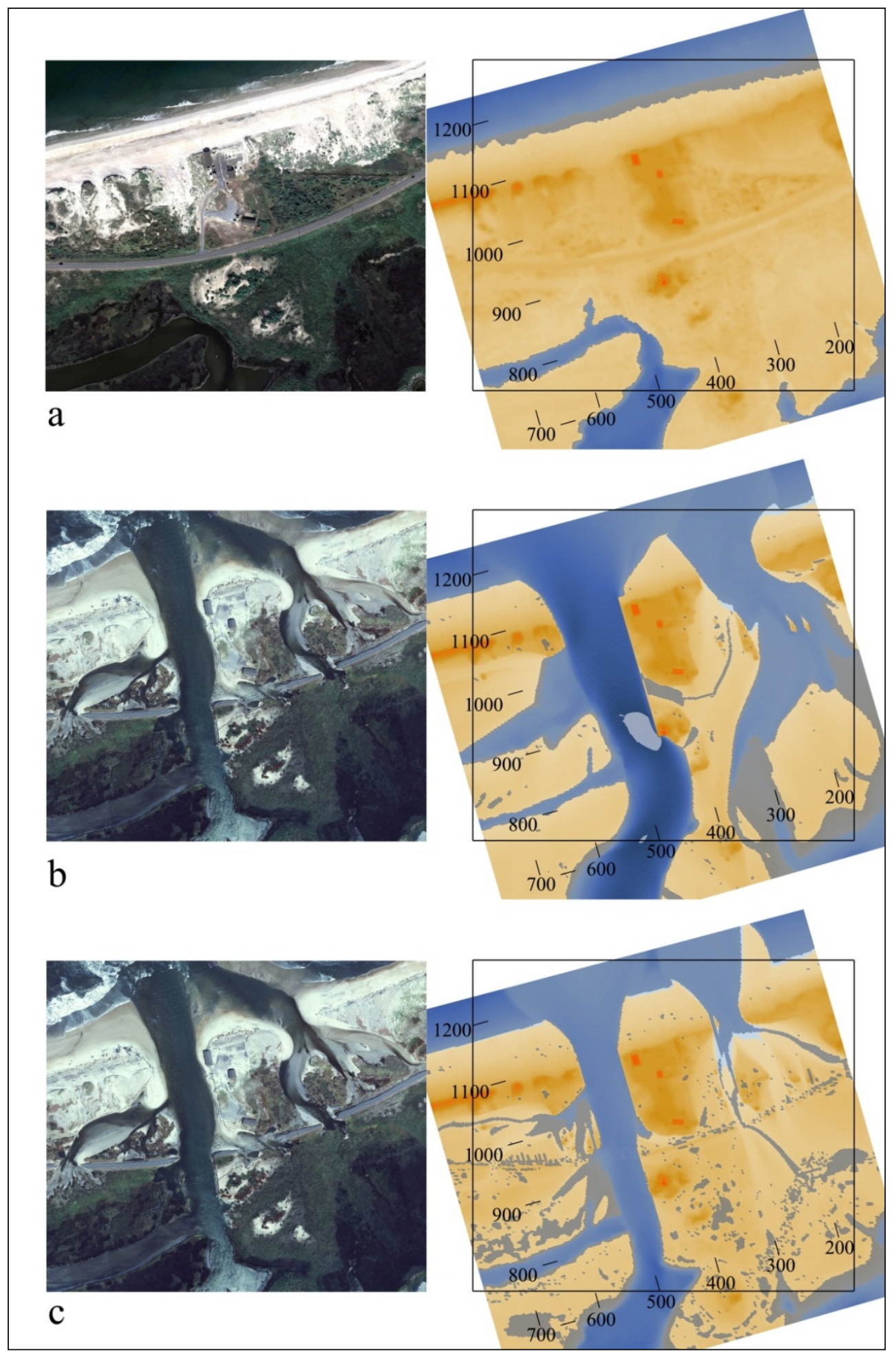

Figure 7. Visual comparison of results. (a) Pre - Irene (Aug. 2nd 2011). (b) Post - Irene (Aug. 30th, 2011) orthoimagery vs Model results (all sand). (c) Post - Irene (Aug. 30th, 2011) orthoimagery vs Model results (land cover). Model results shown on model local coordinates. Black Boxes indicate the orthoimagery coverage. 
Figure 7c depicts the results of the land cover case model run. In this case, the three classes are implemented as described above. The spatial distribution of these classes is illustrated in Figure 6. Clearly the addition of vegetation and pavement altered the patterns of erosion. The most significant impact is in the limited development of the secondary channel. In this case, channelization develops into the dune field but not a significant distance landward of the road. Clearly, more detail on the location and shape of the channels and erosion patterns can only be achieved by employing different sediment classes to mimic the effect of the land cover features. The channelization patterns are similar to what is visible in the orthoimagery of the post storm conditions.

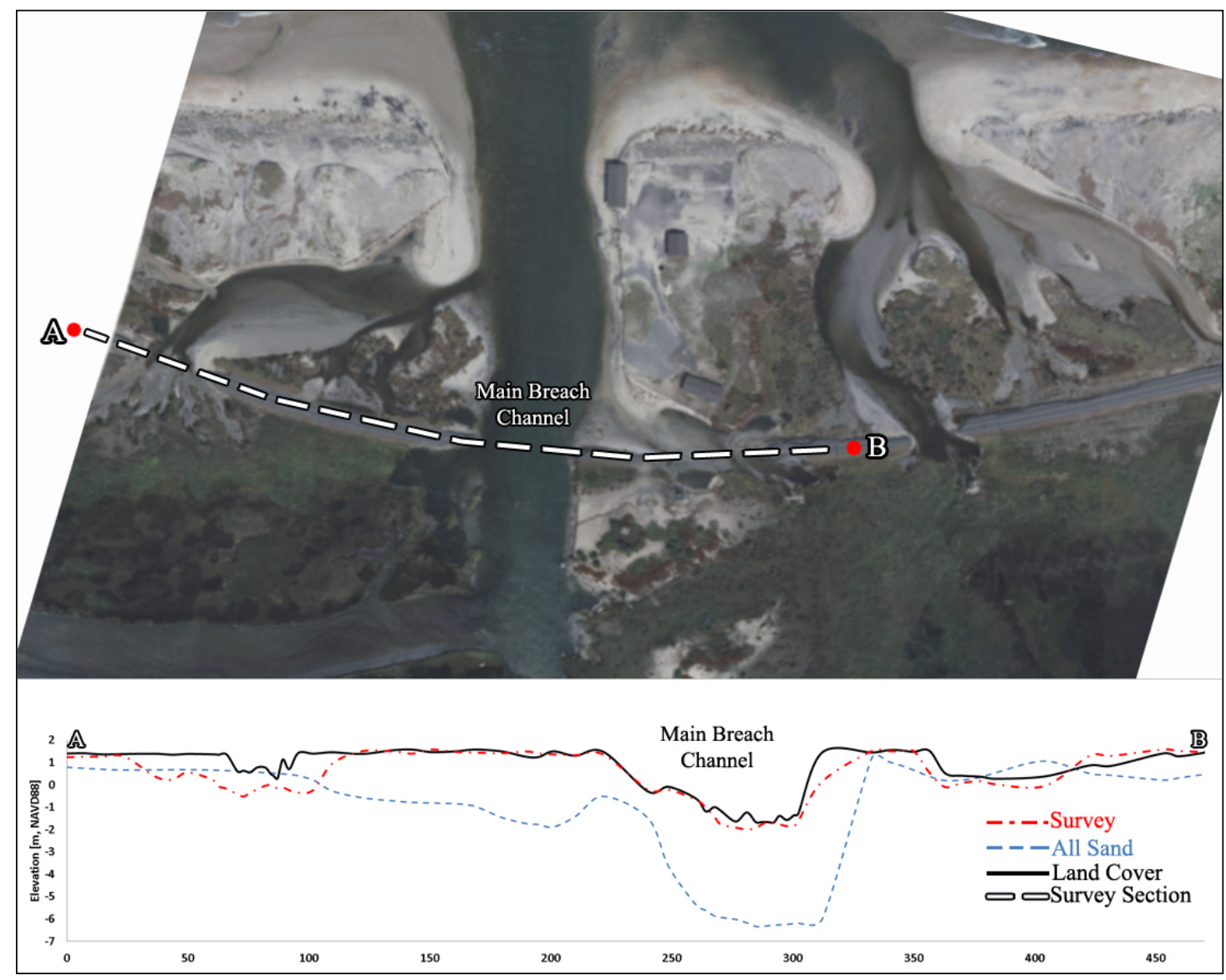

Figure 8. Post storm road survey. Comparison of the model results to the road survey elevations

While the location and morphology of the new channels are important in understanding vulnerable landforms exhibiting tipping point behavior, the depth of channelization (for channels that breach the island) will determine the hydraulic capacity for remaining open as an inlet. NCDOT conducted post storm bathymetric studies in the immediate vicinity of the road to use in developing post storm alternatives for repairing the transportation corridor. These data are invaluable in model validation of depth of erosion. Figure 8 depicts the location of the $470 \mathrm{~m}$ long survey along the road (dashed line from A to B) in the post storm orthoimagery. The graph below the image provides a cross sectional view with distance along the road on the $\mathrm{x}$-axis and elevation relative to NAVD $\mathrm{m}$ on the $\mathrm{y}$-axis. Results from the field survey conducted on August $30^{\text {th }}$, 2011 are plotted in red. The sand only case (blue) is consistent in illustrating a greater tendency to erode. The depth achieved in the main channel is about $6 \mathrm{~m}$, about three times the post storm result. The field survey did not extend to the secondary channel so it is not possible to compare depths developed at that location. The land cover case is in very good agreement with the surveyed elevations in the main channel. Erosion and channelization is underestimated on and around the road at the northern boundary of the study location (approximately at $\mathrm{x}=20-120 \mathrm{~m}$, Figure 8 bottom graph). This is likely to be the effect of the lateral boundary being close to this particular location and extending the grid in this direction could improve results. 


\section{CONCLUSIONS}

Successful prediction of post-storm breach morphology through the implementation of antecedent topographic and land cover conditions and the underlying sediment layers can help answer critical questions on where and how breaches occur during storm events. This information could be critical as coastal communities face post-storm repair decisions and develop long-term comprehensive land use plans. Therefore it is beneficial to implement/consider the effects of the land cover features since different erosion patterns lead to different hydraulic gradient distributions which eventually has an important role on the post storm configuration. In the case presented, simulation results improved by incorporating three sediment classes with vegetation modeled as a two layered system representing the surface and the roots and pavement is modeled as one layer sitting on sand. Using the presented configuration of land cover implementation, the location and morphology of the channelization improved in the planimetric view, the main channel depth was reduced from $6 \mathrm{~m}$ to $2 \mathrm{~m}$ in the cross section view.

Beach and dune erosion models in cases of overland flow need to consider land cover effects. The configuration of the parameters and the layers presented in this case study are the result of a trial and error process; they can be used as a starting point for a similar case. Future work will include a sensitivity analysis of these parameters and applications in multiple new locations. These test cases will include a range of dominant forcing functions (e.g., ocean front wave run-up dominated cases with and without soundside storm surge).

\section{ACKNOWLEDGMENTS}

The authors would like to thank the North Carolina Department of Transportation, U.S Army Corps of Engineers, Renaissance Computing Institute for providing the datasets and the computational resources to make this study possible. This material is based upon work supported by the Coastal Hazards Center of Excellence, a US Department of Homeland Security Science and Technology Center of Excellence under Award Number: 2008-ST-061-ND 0001.

DISCLAIMER: The views and conclusions contained in this document are those of the authors and should not be interpreted as necessarily representing the official policies, either expressed or implied, of the U.S. Department of Homeland Security.

\section{REFERENCES}

Birkemeier, W., Dolan, R. and N. Fisher. 1984. The evolution of a barrier island: 1930-1980. Journal of the American Shore \& Beach Preservation Association, 52(2), 2-12.

Kraus, N.C., and R.A. Wise. 1993. Simulation of January 4, 1992 storm erosion at Ocean City, Maryland, Shore \& Beach 61(1), 34-41.

Kriebel, D.L., and R.G. Dean. 1985. Numerical simulation of time dependent beach and dune erosion, Coastal Engineering, 9, 221-245.

Larson, M., and N.C. Kraus. 1989. SBEACH: numerical model for simulating storm-induced beach change, Report 1: Empirical formulation and model development, U.S. Army Engineer Waterways Experimentation Station, Vicksburg, Miss.

Larson, M., Kubota, S., and L. Erikson. 2001. Modeling sediment transport and profile evolution in the swash zone, Proceedings Coastal Dynamics ’01, ASCE, 908-917.

Larson, M., Wise, R. A., and N.C. Kraus. 2004. Coastal Overwash. Part 2: Upgrade to SBEACH, Regional Sediment Management Demonstration Technical Note, ERDC/RSM-TN-15, U.S. Army Engineer Research and Development Center, Vicksburg, MS.

Larson, M., Wise, R. A., and N.C. Kraus. 2005. Modeling dune response due to overwash transport, Proceedings 29th Coastal Engineering Conference, World Scientific Press, 2133-2145.

Lesser, G., J., J.A. Roelvink, J.A.T.M. van Kester and G.S. Stelling. 2004. Development and validation of a three-dimensional morphological model. Coastal Engineering, 51, 883-915. 
Lindemer, C.A., N.G. Plant, J.A. Puleo, D.M. Thompson and T.V. Wamsley. 2010. Numerical simulation of a low-lying barrier island's morphological response to Hurricane Katrina. Coastal Engineering, 57, 985-995.

McCall, R.T., Van Thiel, J., de Vries, N.G. Plant, A.R. Van Dongeren, J.A. Roelvink and D.M. Thompson. 2010. Two-dimensional time dependent Hurricane overwash and erosional modeling at Santa Rosa Island. Coastal Engineering 57, 668-683.

Morton, R.A. 2002. Factors Controlling Storm Impacts on Coastal Barriers and Beaches: A Preliminary Basis for near Real-Time Forecasting. Journal of Coastal Research, 18(3), 486-501.

Reniers, A.J.H.M., J.A. Roelvink and E.B. Thornton. 2004. Morphodynamic modeling of an embayed beach under wave group forcing. Journal of Geophysical Research, 109 (C01030).

Reniers, A.J.H.M., J. MacMahan, E.B. Thornton and T.P. Stanton. 2006. Modeling infragravity motions on a rip-channel beach. Coastal Engineering, 53, 209-222.

Roelvink, J.A. 1993. Surf beat and its effect on cross-shore profiles. Ph.D. thesis, Delft University of Technology.

Roelvink, J.A., A. Reniers, A. Van Dogeren, Van Thiel, J., de Vries, R., McCall and J. Lescinski. 2009. Modeling storm impacts on beaches, dunes and barrier islands. Coastal Engineering, 56, 11331152.

U.S. Army Corps of Engineers Field Research Facility. 2011. Hurricane Irene Observations at the Field Research Facility. Retrieved from website: http://www.frf.usace.army.mil/irene/irene_obs.pdf.

Van Dongeren, A., A. Reniers, J. Battjes and I. Svendsen. 2003. Numerical modeling of infragravity wave response during DELILAH. Journal of Geophysical Research, 108 (C9).

Vellinga, P. 1983. Predictive computational model for beach and dune erosion during storm surges. Proceedings of Coastal Structures 1983, ASCE, New York, 806-819.

Vellinga, P. 1986. Beach and dune erosion during storm surges, Delft Hydraulics Lab., Publ. No. 372.

Wang, P., J.H. Kirby, J.D. Haber, M.H. Horwitz, P.O. Knorr and J.R. Krock. 2006. Morphological and sedimentological impacts of Hurricane Ivan and immediate poststorm beach recovery along the northwestern Florida barrier-island coasts. Journal of Coastal Research, 22, 1382-1402.

Wang, P. and M.H. Horwitz. 2007. Erosional and depositional characteristics of regional overwash deposits caused by multiple hurricanes. Sedimentology, 54, 545-564.

Wright, L.D., J.M. Swaye and F.J. Coleman. 1970. Effects of Hurricane Camille on the landscape of the Brenton-Chandeleur island chain and the eastern portion of the lower Mississippi delta. Technical Report, 76, 34. Baton Rouge: Louisiana State University Coastal Studies Institute. 